IBIMA Publishing

Journal of Research and Practice in Dentistry

http://www.ibimapublishing.com/journals/DENT/dent.html

Vol. 2014 (2014), Article ID 821205, 11 pages

DOI: $10.5171 / 2014.821205$

Research Article

\title{
Obturation Effect of Different Filling Techniques on Isthmuses in Mandibular Molars after Passive Ultrasonic Irrigation
}

\author{
Nimet Gençoğlu' ${ }^{1}$, Mustafa Gündoğar², Dilek Helvacıoğlu-Yiğit ${ }^{3}$ \\ and Cafer Türkmen ${ }^{1}$ \\ ${ }^{1}$ Marmara University Faculty of Dentistry, Department of Restorative Dentistry, istanbul, Turkey \\ ${ }^{2}$ Medipol University Faculty of Dentistry, Department of Endodontics, ìstanbul, Turkey \\ ${ }^{3}$ Kocaeli University Faculty of Dentistry, Department of Endodontics, Kocaeli, Turkey
}

Correspondence should be addressed to: Nimet Gençoğlu; ngencoglu@hotmail.com

Received 17 May 2013; Accepted 19 June 2013; Published 24 January 2014

Academic Editor: Alfred Naaman

Copyright @ 2014 Nimet Gençoğlu, Mustafa Gündoğar, Dilek Helvacıoğlu-Yiğit and Cafer Türkmen. Distributed under Creative Commons CC-BY 3.0

\begin{abstract}
The effect of ultrasonic debridement on cleaning isthmuses and the effect of obturation techniques on filling of isthmuses in mandibular first molars were evaluated.

Sixty molars with two mesial canals were instrumented by rotary instruments, divided into four groups (15 each). Group $1 \& 2$ were irrigated by PUI (passive ultrasonic irrigation) or by hand irrigation with \%5.25 NaOCl and not obturated. Group $3 \& 4$ obturated by Microseal or lateral condensation after passive ultrasonic irrigation. The roots were sectioned at horizontally different levels, the quantity of debris was evaluated under stereomicroscope and the percentage of obturated area in isthmus was statistically analyzed (ANOVA and NewmanKeuls).
\end{abstract}

The highest incidence of isthmus was found in the $3.5 \mathrm{~mm}$ sections of the roots.

PUI was found to be more effective than hand irrigation to clean isthmuses in mandibular molars $(p<0.05)$. More gutta-percha content was found in Microseal obturation than lateral condensation $(\mathrm{p}<0.05)$.

Ultrasonic instruments were found to be effective to clean isthmuses and Microseal was superior to lateral condensation technique on obturating isthmuses.

Keywords: Isthmus, microseal, ultrasonic irrigation.

Cite this Article as: Nimet Gençoğlu, Mustafa Gündoğar, Dilek Helvacıoğlu-Yiğit and Cafer Türkmen (2014), "Obturation Effect of Different Filling Techniques on Isthmuses in Mandibular Molars after Passive Ultrasonic Irrigation," Journal of Research and Practice in Dentistry, Vol. 2014 (2014), Article ID 821205, DOI: $10.5171 / 2014.821205$ 


\section{Introduction}

The main objective of endodontic therapy is to clean the entire pulp cavity and complete it with an inert filling material. Because the root canal system has a complex anatomy, it is difficult to shape and clean the root canal completely. Small isthmuses and irregularities have been shown to be inaccessible to conventional hand and rotary instrumentation. ${ }^{1}$ Ingle $^{2}$ concluded that $60 \%$ of endodontic failures are caused by incomplete obturation of the root canal. The other main reasons include untreated canals, accessory canals and the presence of an isthmus.

Isthmuses are present in all types of roots in which two canals are normally found. ${ }^{3}$ The incidence of isthmus was found around $\% 30$ in mandibular premolar, $60 \%$ in mesiobuccal roots of maxillary first molar with two canals. ${ }^{4}$ However, the prevalence of isthmuses in the mesial root of mandibular molars has been observed to be as high as $80 \% .^{5}$ They are poorly accessible to root canal instruments and untreated isthmuses can cause failure of conventional root canal therapy or apical surgery, especially in posterior teeth.

The outcome of endodontic treatments is improved by the development of new techniques and new instruments. The use of ultrasonics in endodontics has made it especially easy to clean difficult anatomical features like accessory canals and isthmuses. The first findings on the technique of root canal therapy using an ultrasonic instrument were reported by Richman. ${ }^{6}$ Martin et al. ${ }^{7}$ found that the root canals of teeth that were ultrasonically filed and irrigated were cleaner when compared with the conventional methods, and that the smear layer appeared to be greatly reduced. The cleaning efficacy of ultrasound appears to be promising when used only for irrigation after the root canal has been instrumented. ${ }^{8}$ Weller et al. ${ }^{9}$ concluded that the most effective debridement occurred when ultrasonication was used after completion of hand instrumentation. It has also been demonstrated that an irrigant in conjunction with ultrasonic vibration, which generates a continuous movement of the irrigant, is directly associated with the effective cleaning of the root canal space. Ahmad et al. ${ }^{8}$ described that when files were activated with ultrasonic energy, acoustic streaming was sufficient to produce cleaner canals, compared with hand filing alone. They showed that the flushing action of irrigants could be enhanced by using ultrasonication. $8,10,11$ This seemed to improve the efficacy of irrigation solutions in removing organic and inorganic debris from root canal walls. ${ }^{2,7,12}$

In the past, the canal isthmus was often overlooked and it was also difficult to prepare if located. However, previous studies showed that passive ultrasonic irrigation removed more dentin debris from the isthmus, oval extensions in the root canal and irregularities from the root canal wall. ${ }^{1}$ The recognition and management of the canal isthmus is an important factor that may improve the success rate of surgical and non surgical endodontics specially in posterior teeth. ${ }^{13}$

There are a few studies on the subject of the cleaning of isthmuses ${ }^{1,6,9}$ but none on obturating them. Because the isthmuses usually have the vital and infected part of the pulp, if it had not been cleaned and obturated during the conventional root canal treatment or before surgical procedure, it could contribute to failure of the case. Nowadays, it is possible to clean isthmuses by using ultrasonics and then to obturate them by using the warm guttapercha technique. The aim of this study was to investigate the cleaning action of ultrasonic irrigation and the obturation effect of different techniques on isthmuses in mandibular molars.

\section{Materials and Methods}

Sixty extracted first mandibular molars with two mesial canals in one root exhibiting a single oval foramen were selected. The access cavity was opened and all canals were instrumented by using rotary Hero Shaper instruments (Micro Mega, Besancon, France). According to the manufacturer instruction, each canal was 
instrumented by No \# 25 file with $\% 6$ and $4 \%$ taper and finally with \#30\% 4 taper instrument. The canals were irrigated by $2 \mathrm{ml}$ of $5.25 \% \mathrm{NaOCl}$ solution after each instrument usage. The experimental teeth were divided equally into 4 groups:

\section{Experimental Group}

Group 1. The teeth were irrigated by using passive ultrasonic irrigation (PUI) $(n=15)$.

Group 2. The teeth were irrigated by hand irrigation $(n=15)$.

Group 3. The teeth were obturated by warmed lateral condensation of guttapercha technique (Microseal) after irrigation by PUI $(n=15)$.

Group 4. The teeth were obturated by cold lateral condensation of gutta percha after irrigation by PUI $(n=15)$.

\section{Group 1 (PUI)}

Ultrasonic irrigation was performed according to the manufacturer's instructions (at the highest power setting for $60 \mathrm{~s}$ ) and applied in each mesial canal of the teeth with approximately $2 \mathrm{ml}$ of 5.25 $\% \mathrm{NaOCl}$ by using ultrasonically activated size \#15 endo file (EMS, Nyon, Switzerland, DT_006, 007, 008, 009, 010).

\section{Group 2 (Conventional Irrigation)}

The mesial canals were irrigated with $2 \mathrm{ml}$ of $5.25 \% \mathrm{NaOCl}$ and $2 \mathrm{ml}$ of $17 \%$ EDTA by using a syringe gauge $(2 \mathrm{ml})$ for $60 \mathrm{~s}$.

\section{Groups 3 and Group 4 (Obturated after PUI)}

Mesial canals of 15 teeth were obturated by the Microseal technique (group 3) and the remaining 15 teeth were obturated by the lateral condensation technique (group 4) after ultrasonic irrigation by $5.25 \% \mathrm{NaOCl}$, using the ultrasonically activated size \#15 endo file for $1 \mathrm{~min}$.

Obturation Microseal Technicus (Tycom, Irvine, CA, USA): An appropriate size of master cone was placed into each mesial canal until tug-back was elicited. The appropriate spreader was selected to compact the master cone, $1.0 \mathrm{~mm}$ shorter than the working length. Finally, the appropriate accessorymechanical compactors were selected, according to the manufacturer's instructions. Freshly mixed Kerr sealer was placed into each mesial canal and sealer-covered master guttapercha was seated. The spreader was advanced alongside the master cone at the working length for compaction. A tapered void was formed between the compacted gutta-percha cone and the root canal walls by the withdrawal of the spreader from the canal. The appropriate compactor was placed in the heated gutta-percha cartridge and was sealed with a uniform layer of material. The gutta-percha-coated compactor was then inserted to the void previously created in the canal by the spreader, and was applied as close to the working length as possible, avoiding rotation as it was inserted. A resisting force was applied to the compactor's backing-out motion without any apical pressure and rotation of the compactor was started at a speed of $6000 \mathrm{rpm}$. The compactor was removed after approximately 3 seconds. Rotation continued until the compactor was removed fully from the canal. If the canal was not completely obturated, more gutta-percha cones were placed on the compactor. Protruding gutta-percha and sealer were removed from the access cavity by using a cotton pellet.

\section{Obturation Lateral Condensation} Technique: No \#35 gutta-percha master cone (Hygenic Corp, Akron, Ohio) was fitted to within $0.5 \mathrm{~mm}$ of the working length of each mesial canal. Freshly mixed Kerr sealer was placed into the canal. Appropriate spreader was inserted $1 \mathrm{~mm}$ shorter than the working length. No \#25 gutta-percha cone was inserted as an accessory cone followed by smaller size spreader insertion. This procedure was continued until the canal was considered to be obturated adequately with smaller size of points, and spreader could no longer penetrate beyond the coronal third of the canal. After complete canal obturation the coronal gutta-percha was removed with a hot instrument. 
All distal roots were removed and the mesial roots were embedded in orthodontic clear acrylic resin. A rotary saw with a diamond blade water (Isomet, Buehler; USA) was used to make crosssectional slides through the embedded teeth. To reduce a smear layer of guttapercha, the sections were made using coldwater irrigation. The roots were sectioned at $1.5 \mathrm{~mm}, 2.5 \mathrm{~mm}, 3.5 \mathrm{~mm}$ and $4.5 \mathrm{~mm}$ from the anatomic apex. Unobturated canals were dyed with $2 \%$ methylene blue to expose the debris and isthmus better under the microscope.

Photographs of every section from all the groups were taken at an original 50X magnification by means of a stereomicroscope (Imaging Systems, Leica Ltd, Cambridge, England) with a digital camera (Fig. 1-4).

1. The incidence of isthmus was recorded according to the classification used by $\mathrm{Hsu}$ and Kim. ${ }^{3}$

2. The amount of debris in the isthmus was classified by using the scoring system reported by van de Sluis and Wesselink. ${ }^{14} \mathrm{~A}$ higher score indicated a greater amount of debris:

Score 0: The entire isthmus was free of debris
Score 1: Less than half of the isthmus was filled with debris

Score 2: Half and more than the half of the isthmus was filled with debris

Score 3: The entire isthmus was filled with debris

The examination was performed by three independent investigators using this scoring system.

For statistical analysis, the Kruskal-Wallis test was used. The level of significance was set at $\mathrm{p}=0.05$.

3. The areas of the canal and gutta-percha, sealer or voids were outlined and then measured by Image pro-plus computer program (IPWIN application, Media Cybernetics, Inc.) for both obturation techniques. All measurements were evaluated by means of one way ANOVA and the Newman-Keuls test.

\section{Results}

The incidence of an isthmus is shown in Table 1. The highest incidence of isthmus was found in the $3.5 \mathrm{~mm}$ sections of the roots.

\section{Table 1. Incidence of an İsthmus at Each Level}

\begin{tabular}{|c|c|}
\hline $\begin{array}{c}\text { Level from apex } \\
\text { (mm) }\end{array}$ & $\begin{array}{c}\text { Percent of isthmuses (\%) } \\
\text { (n= 60 teeth) }\end{array}$ \\
\hline 1.5 & 38.3 \\
\hline 2.5 & 48.3 \\
\hline 3.5 & 53.3 \\
\hline 4.5 & 43.3 \\
\hline
\end{tabular}

The use of ultrasound irrigation (Fig. 1) after rotary instrumentation resulted in better cleanliness of the isthmus compared with hand irrigated specimens (Fig. 2),(Table 2) in all levels (Group 1 versus 2) $(\mathrm{p}<0.05)$. 


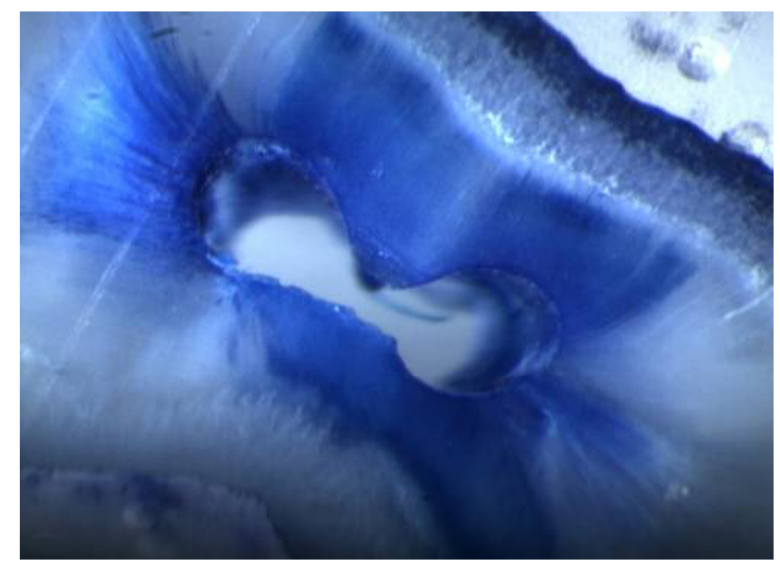

Fig. 1: Cross Section of a Root Canal Isthmus irrigated with PUI

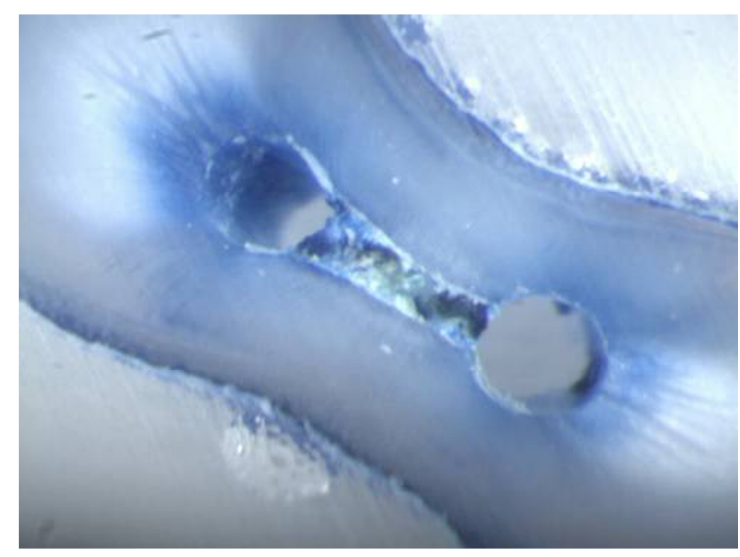

Fig. 2: Cross Section of a Root Canal Isthmus Irrigated with Hand Irrigation 
Table 2. Amount of Debris for Each Group

\begin{tabular}{|c|c|c|c|c|}
\hline Tooth No. & SL (mm) & PUI & SL (mm) & Hand Irr. \\
\hline \multirow{3}{*}{1} & 1.5 & 1 & 1.5 & 1 \\
\hline & 2.5 & 0 & 2.5 & 3 \\
\hline & 3.5 & 1 & 3.5 & 3 \\
\hline \multirow[t]{3}{*}{2} & 1.5 & 0 & 1.5 & 2 \\
\hline & 2.5 & 0 & 2.5 & 3 \\
\hline & 3.5 & 0 & 3.5 & 3 \\
\hline \multirow[t]{3}{*}{3} & 1.5 & 0 & 1.5 & 2 \\
\hline & 2.5 & 0 & 2.5 & 3 \\
\hline & 3.5 & 0 & 3.5 & 3 \\
\hline \multirow[t]{3}{*}{4} & 1.5 & 0 & 1.5 & 3 \\
\hline & 2.5 & 0 & 2.5 & 3 \\
\hline & 3.5 & 0 & 3.5 & 3 \\
\hline \multirow[t]{3}{*}{5} & 1.5 & 0 & 1.5 & 3 \\
\hline & 2.5 & 0 & 2.5 & 1 \\
\hline & 3.5 & 0 & 3.5 & 1 \\
\hline \multirow[t]{3}{*}{6} & 1.5 & 0 & 1.5 & 3 \\
\hline & 2.5 & 0 & 2.5 & 3 \\
\hline & 3.5 & 1 & 3.5 & 3 \\
\hline \multirow[t]{3}{*}{7} & 1.5 & 2 & 1.5 & 1 \\
\hline & 2.5 & 2 & 2.5 & 1 \\
\hline & 3.5 & 2 & 3.5 & 1 \\
\hline \multirow[t]{3}{*}{8} & 1.5 & 2 & 1.5 & 1 \\
\hline & 2.5 & 0 & 2.5 & 3 \\
\hline & 3.5 & 0 & 3.5 & 1 \\
\hline \multirow[t]{3}{*}{9} & 1.5 & 1 & 1.5 & 3 \\
\hline & 2.5 & 0 & 2.5 & 3 \\
\hline & 3.5 & 0 & 3.5 & 3 \\
\hline \multirow[t]{3}{*}{10} & 1.5 & 1 & 1.5 & 1 \\
\hline & 2.5 & 0 & 2.5 & 1 \\
\hline & 3.5 & 0 & 3.5 & 1 \\
\hline \multirow[t]{3}{*}{11} & 1.5 & 2 & 1.5 & 3 \\
\hline & 2.5 & 1 & 2.5 & 3 \\
\hline & 3.5 & 2 & 3.5 & 3 \\
\hline \multirow[t]{3}{*}{12} & 1.5 & 2 & 1.5 & 3 \\
\hline & 2.5 & 1 & 2.5 & 3 \\
\hline & 3.5 & 1 & 3.5 & 3 \\
\hline \multirow[t]{3}{*}{13} & 1.5 & 2 & 1.5 & 2 \\
\hline & 2.5 & 0 & 2.5 & 2 \\
\hline & 3.5 & 0 & 3.5 & 3 \\
\hline \multirow[t]{3}{*}{14} & 1.5 & 0 & 1.5 & 2 \\
\hline & 2.5 & 0 & 2.5 & 2 \\
\hline & 3.5 & 0 & 3.5 & 3 \\
\hline \multirow[t]{3}{*}{15} & 1.5 & 0 & 1.5 & 3 \\
\hline & 2.5 & 0 & 2.5 & 3 \\
\hline & 3.5 & 0 & 3.5 & 3 \\
\hline
\end{tabular}

When the obturation techniques were compared, the Microseal technique (Fig. 3) was found to be superior to the lateral condensation technique (Fig. 4) in obturating isthmuses after irrigation by ultrasonics. The gutta percha and sealer contents in the two techniques are shown in Table 3. 


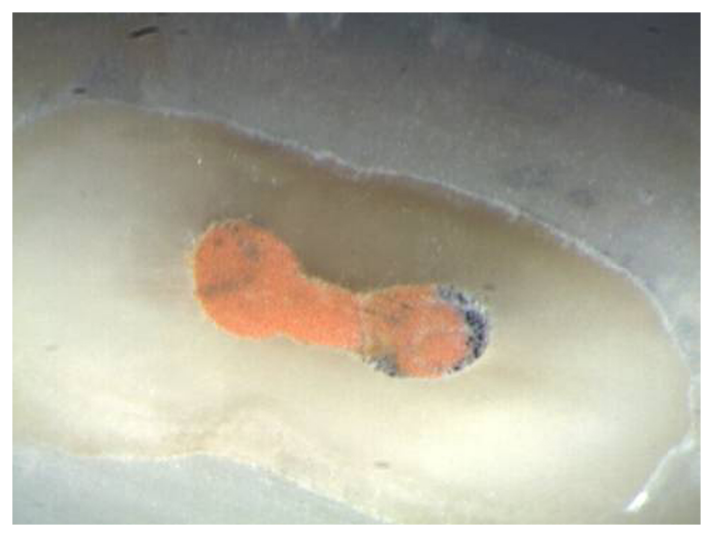

Fig. 3: Cross Section of a Root Canal Filled with Microseal, $2.5 \mathrm{~mm}$ from the Apex

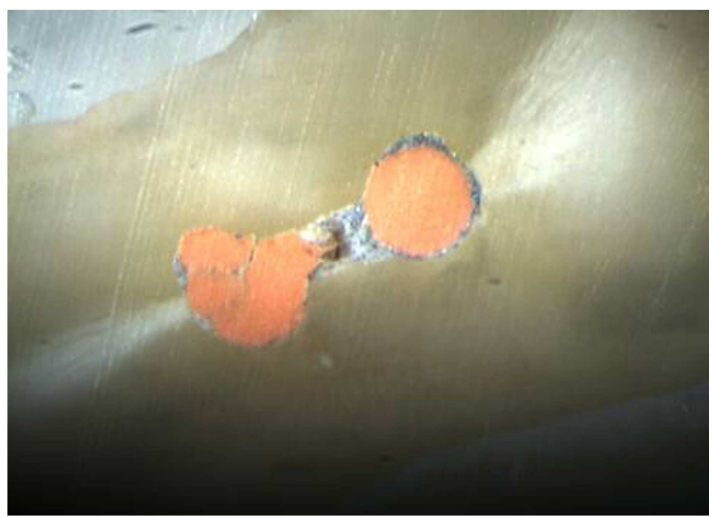

Fig. 4: Cross Section of a Root Canal Filling with Lateral Condensation, $2.5 \mathrm{~mm}$ from the Apex

Table 3. Content of Gutta Percha and Sealer of Two Techniques

\begin{tabular}{|c|c|c|}
\hline Obturation Technique & $\begin{array}{c}\text { Gutta-percha } \\
\text { + Sealer } \\
\text { (\%) }\end{array}$ & $\begin{array}{c}\text { Mean } \\
\text { (SD) }\end{array}$ \\
\hline Microseal & $\% 96,22^{*}$ & $\pm 4,41$ \\
\hline Lateral Condensation & $\% 89,77^{*}$ & $\pm 8,84$ \\
\hline${ }^{*}(p<0.05)$
\end{tabular}

\section{Discussion}

Isthmus which is described as anastomosis or corridor between two canals is a significant factor in the thorough debridement of the root canal system specifically in maxillary and mandibular molars. Studies have shown that the highest isthmus incidence was found in mesial canals of mandibular first molars range between $63 \%$ and $100 \%$. Also, the highest incidence of isthmus was found at 4 to $6 \mathrm{~mm}$ from apex.. ${ }^{3}$ In the present study, the highest isthmus incidence was found in $3.5 \mathrm{~mm}$ of apex in mesial canals of mandibular first molars. These findings are quite important especially in apicoectomy since failures rate are quite high in premolars and molars surgery that may be due to isthmuses.

This study showed that passive ultrasonic irrigation cleaned up the irregularities of the root canals, such as isthmuses, better 
than hand irrigation. This finding can be attributed to the action of the ultrasonically activated irrigation solution within the canal system. Isthmus cleanliness values improved significantly from the $1.5 \mathrm{~mm}$ to the $3 \mathrm{~mm}$ level when passive ultrasonic irrigation was used after rotary instrumentation.

The effect of irrigation time when using ultrasonic irrigation is not clear in literature. Sabin et al. ${ }^{15}$ reported that $30 \mathrm{~s}$ to $1 \mathrm{~min}$ of ultrasonic activation was sufficient to produce clean canals, whereas Krell et al. ${ }^{16}$ recommended the use of ultrasonic irrigation for $2 \mathrm{~min}$. Van de Sluis et al. ${ }^{14}$ found that a $3 \mathrm{~min}$ ultrasonic irrigation was effective to remove dentine debris. In the present study, $1 \mathrm{~min}$ ultrasonic irrigation seemed to be effective in cleaning isthmuses.

Tauber et al. ${ }^{17}$ and Goldman et al. ${ }^{18}$ reported that low power ultrasonication was not effective when used for the irrigation of the canals. Cameron ${ }^{19}$, however, showed that the use of medium power was effective in cleaning root canals. In this study, the highest power setting was used for ultrasonic irrigation according to the manufacturer's recommendation.

Two types of ultrasonic irrigation are described in the literature: one type where irrigation is combined with simultaneous ultrasonic instrumentation (UI), and the other without simultaneous instrumentation, called passive ultrasonic irrigation (PUI). ${ }^{20}$ Weller et al. ${ }^{9}$ showed that UI is less effective in removing simulated pulp tissue from the root canal system, or the smear layer from the root canal wall, than PUI. Ahmad et al. $^{8}$ explained that this could be the result of a reduction of acoustic streaming and cavitation. In the present study, the EMS Endo file was used to perform passive ultrasonic irrigation and found to be effective in cleaning the isthmuses of the root canal.

Cuningham et al. ${ }^{21}$ have demonstrated that ultrasonics can also improve the disinfection of root canals. The studies showed that passive ultrasonic irrigation is significantly better than syringe irrigation in the reduction of bacteria in the root canals. Walmsley 22 reported that this could be because of the disruption of organic tissues entering the streaming field that was generated. Ahmad 23 explained that ultrasonically activated files generate a mechanism that damages biological cells. Lee et al. ${ }^{1}$ found that a lower number of colonies survived when ultrasonic activation was used. Carver et al..$^{24}$ also found that ultrasonic irrigation following hand/rotary instrumentation in vivo decreased significantly the number of bacteria to a greater extent than hand/rotary instrumentation alone. Despite these findings, it generally accepted that no technique is able to ensure complete canal disinfection.

Previous studies have shown that some endodontic sealers are soluble ${ }^{25}$ and may shrink slightly. ${ }^{26}$ Sealer dissolution may trigger an increase in leakage along the root filling over time. So, generally it is preferred to minimize the amount of sealer and maximize the volume of gutta-percha. Eguchi et al. ${ }^{27}$ reported that lateral condensation results in excessive amounts of sealer and apical voids. Peters ${ }^{25}$ also found voids, spreader tracts, incomplete fusion of the gutta-percha cones, and lack of surface adaptation in lateral condensation technique. In our previous study ${ }^{28}$, the gutta-percha/sealer content of different warmed condensation techniques were compared with lateral condensation and all warmed condensation techniques (included Microseal) were found superior to lateral condensation technique. In the present study, again Microseal technique was found to be superior to lateral condensation technique with regard to gutta-percha-sealer content.

In literature, studies have been performed concerning the microleakage effect of different obturation techniques rather than that of the gutta-percha content. Hwang et al. ${ }^{29}$ investigated the microleakage effect of Microseal, warm vertical condensation and lateral condensation techniques on obturation of isthmuses in multi-rooted teeth, and found that the Microseal technique was superior to other 
techniques. Davalou et al. $^{30}$ reported no significant difference in apical leakage between the System B and Microseal techniques. Recently, Mazotti et al. ${ }^{31}$ compared Microseal to hybrid ENAC ultrasonic and lateral condensation technique and found the best results in Microseal obturation. When the studies were compared to literature, contradictory results could be found between leakage studies even when the same materials have been studied. The lack of standardization of the experimental techniques leads to conflicting results. Also, the clinical significance of leakage tests in vitro is questionable, but incompletely filled canal irregularities such as isthmuses with the assumption that this meant apical leakage was occurring. Also, reducing the ratio of sealer to gutta-percha may improve the long term seal provided by the root canal filling.

Although these are in vitro results, they are of significance because these factors cannot easily be quantitatively determined in vivo. Nevertheless, further clinical studies are necessary to confirm these results and evaluate their relevance to treatment outcome.

\section{References}

1. Lee, S. J., Wu, M. K. \& Wesselink, P. R. (2004). "The Effectiveness of Syringe Irrigation and Ultrasonics to Remove Debris from Stimulated Irregularities within Prepared Root Canal Walls," International Endodontic Journal 2004; 37:672-8.

2. Luebke, R. G., Glick, D. H. \& Ingle, J. I. (1964). "Indications and Contraindications for Endodontic Surgery," Oral Surgery, Oral Medicine, Oral Pathology 1964; 18:97-113.

3. Hsu, Y. Y. \& Kim, S. (1997). "The Resected Root Surface. The Issue of Canal Isthmuses," Dental Clinics of North America 1997; 41:529-40.

4. Cambruzzi, J. V. \& Marshall, F. J. (1983). "Molar Endodontic Surgery," Journal
(Canadian Dental Association) 1983; 1:61-6.

5. Vertucci, F. J. (1984). "Root Canal Anatomy of the Human Permanent Teeth," Oral Surgery, Oral Medicine, Oral Pathology 1984; 58:589-99.

6. Richman, M. J. (1957). 'The Use of Ultrasonics in Root Canal Therapy and Root Resection,' Journal of Dental Medicine 1957; 12:12-8.

7. Martin, H., Cunningham, W. T. \& Norris, J. P. (1980). "A Quantitative Comparison of the Ability of Diamond and K-Type Files to Remove Dentin," Oral Surgery, Oral Medicine, Oral Pathology 1980; 50:566-8.

8. Ahmad, M., Pitt Ford, T. R. \& Crum, L. A. (1987). "Ultrasonic Debridement of Root Canals: Acoustic Streaming and its Possible Role," Journal of Endodontics 1987; 13:490-9.

9. Weller, R. N., Brady, J. M. \& Bernier, W. E. (1980). "Efficacy of Ultrasonic Cleaning," Journal of Endodontics 1980; 6:740-3.

10.Stock, C. J. (1991). "Current Status of the Use of Ultrasound in Endodontics," International Dental Journal 1991; 4:175-82.

11.Cheung, G. S. P. \& Stock, C. J. R. (1993). "In Vitro Cleaning Ability of Root Canal Irrigants with and without Endosonics," International Endodontic Journal 1993; 26:334-43.

12.Ferreira, R. B., Alfredo, E., Porto de Arruda, M., Silva Sousa, Y. T. \& SousaNeto, M. D. (2004). "Histological Analysis of the Cleaning Capacity of Nickel-Titanium Rotary Instrumentation with Ultrasonic Irrigation in Root Canals," Australian Endodontic Journal 2004; 30: 56-8.

13.Weller, R. N., Niemczyk, S. P. \& Kim, S. (1995). "Incidence and Position of the Canal Isthmus. Part 1.Mesiobuccal Root 
of the Maxillary First Molar," Journal of Endodontics 1995; 21:380-3.

14.Van de Sluis, L. W. M, Wu, M.- K. \& Wesselink, P. R. (2005). "A Comparison between a Smooth Wire and a K-File in Removing Artificially Placed Dentine debris from Root Canals in Resin Blocks during Ultrasonic Irrigation," International Endodontic Journal 2005; 38:593-6.

15.Sabins, R. A., Johnson, J. D. \& Hellstein, J. W. (2003). "A Comparison of the Cleaning Efficacy Short-Term Sonic and Ultrasonic Passive Irrigation after Hand Instrumentation in Molar Root Canals," Journal of Endodontics 2003; 29:674-8.

16.Krell, K. V., Johnson, R. J. \& Madison, S. (1988). "Irrigation Pattern during Ultrasonic Canal Instrumentation. Part I. K-Types Files," Journal of Endodontics 1988; 14:65-8.

17.Tauber, R., Morse, D. R., Sinai, I. A. \& Furst, M. L. (1983). "A Magnifying Lens Comparative Evaluation of Conventional and Ultrasonically Energized Filling," Journal of Endodontics 1983; 9:269-74.

18.Goldman, M., White, R. R., Moser, C. R. \& Tenca, J. I. (1988). "A Comparison of Three Methods of Cleaning and Shaping the Root Canal in Vitro," Journal of Endodontics 1988; 14:7-12.

19.Cameron, J. A. (1982). "The Use of Ultrasound in the Cleaning of Root Canals: A Clinical Report," Journal of Endodontics 1982; 8: 471-3.

20.Van de Sluis, L. W. M., Versluis, M., Wu, M. K. \& Wesselink, P. R. (2007). "Passive Ultrasonic Irrigation of the Root Canal: A Review of the Literature," International Endodontic Journal 2007; 40: 415-26.

21.Cunningham, W. T., Martin, H., Pelleu, G. B. \& Stoops, D. E. (1982). “A Comparison of Antimicrobial Effectiveness of Endosonic and Hand Root Canal
Therapy," Oral Surgery, Oral Medicine, Oral Pathology 1982;54:238-41.

22.Wamsley, A. D. (1987). "Ultrasound and Root Canal Treatment: The Need for Scientific Evaluation," International Endodontic Journal 1987; 20:105-11.

23.Ahmad, M. (1989). "Effect of Ultrasonic Instrumentation on Bacteroides Intermedium," Dental Traumatology 1989; 5:83-6.

24.Carver, K., Nusstern, J. \& Reader, A. (2007). "Adding Ultrasonic Irrigation to Endodontic Therapy," Journal of Endodontics 2007; 53:199-200.

25.Peters, D. D. (1986). "Two Year in Vitro Solubility Evaluation of four Gutta-Perch Sealer Obturation Techniques," Journal of Endodontics 1986; 12:139-45.

26.Weiner, B. H. \& Schilder, H. (1971). “A Comparative Study of the Important Physical Properties of Various Root Canal Sealers. II. Evaluations of Dimensional Changes," Oral Surgery, Oral Medicine, Oral Pathology 1971; 32:928-36.

27.Eguchi, D. S., Peters, D., Hollinger, J. O. \& Lorton, L. (1985). "A Comparison the Area of the Canal Space occupied by Gutta-Percha Following Four GuttaPercha Obturation Techniques Using Procosol Sealer," Journal of Endodontics 1985; 11:66-75

28.Gencoglu, N. (2003). "Comprasion of 6 Different Gutta-Percha Techniques (part II): Thermafil, JS Quick- Fill, Soft Core, Microseal, System B, and Lateral Condensation," Oral Surgery, Oral Medicine, Oral Pathology, Oral Radiology and Endodontology 2003; 96:91-5.

29.Hwang, H. K., Jou, S. \& Kim, S. (1998). 'Sealing Ability of Isthmuses by Different Obturation Techniques,' Journal of Endodontics 1998; 24: 283-5. 
30.Davalou, S., Guttman, J. L. \& Nunn, M. H. (1999). "Assessment of Apical and Coronal Root Canal Seals Using Contemporary Endodontic Obturation and Restorative Materials and Techniques," International Endodontic Journal 1999; 32:388-96.

31.Mazotti, D., Sivieri-Araujo, G., Berbert, F. L. \& Bonetti-Filho, I. (2008). "In Vitro Evaluation of the Obturation Ability, Adaptation and Compaction of GuttaPercha in the Root Canal System Employing Different Filling Techniques," Acta Odontologica Latinoamericana 2008; 21:3-9. 